\title{
A Novel Photoelectrochemical Sensor for Thiamphenicol Based on Porous Three-Dimensional Imprinted Film
}

\author{
Guangming Yang ${ }^{1, *}$, Xianlan Chen ${ }^{1}$, Qingshan Pan ${ }^{1}$, Wei Liu ${ }^{1, *}$ and Faqiong Zhao ${ }^{2, *}$ \\ ${ }^{1}$ Key Laboratory of Local Characteristic Resource Utilization and New Materials of Yunnan, \\ College of Science, Honghe University, Mengzi 661100, PR China \\ ${ }^{2}$ Key Laboratory of Analytical Chemistry for Biology and Medicine (Ministry of Education), College \\ of Chemistry and Molecular Sciences, Wuhan University, Wuhan 430072, PR China \\ *E-mail: yangguangmingbs@126.com, liuwei4728@163.com, fqzhao@whu.edu.cn
}

doi: $10.20964 / 2017.08 .34$

Received: 8 October 2016 / Accepted: 30 May 2017 / Published: 12 July 2017

\begin{abstract}
In this study, we designed a novel photoelectrochemical (PEC) sensor for thiamphenicol (TAP), which based on porous graphene (P-r-GO), $\mathrm{MoS}_{2}$ nanoflower, dendritic Pt-Pd NPs (Pt-Pd NPs), amino multiwalled carbon nanotubes ( $\mathrm{NH}_{2}$-MWCNTs), molecularly imprinted polymer (MIP) and L-shape glassy carbon electrode (L-GCE). Firstly, $\mathrm{MoS}_{2}$ and P-r-GO nanoflower composite was prepared by one-step hydrothermal method. Then, this composite suspension was coated on L-GCE surface to virtually form a porous interface. After that, the suspension of Pt-Pd NPs and $\mathrm{NH}_{2}-\mathrm{MWCNTs}$ was dropped onto $\mathrm{MoS}_{2}$-P-r-GO / L-GCE. Subsequently, TAP was imprinted on above modified electrode by cyclic voltammetry as o-phenylenediamine was monomer. Afterwards, ascorbic acid was selected as a photocurrent probe when TAP was removed from MIP film and adsorbed on sensing surface. The resulting PEC sensor possessed excellent response for TAP, and its linear range was $1.0 \times 10^{-9} \sim 3.5 \times$ $10^{-6} \mathrm{~mol} \mathrm{~L}{ }^{-1}$ with the detection limit of $5.0 \times 10^{-10} \mathrm{~mol} \mathrm{~L}^{-1}$. This sensor was used to determine TAP in real food samples with favorable results.
\end{abstract}

Keywords: Photoelectrochemical sensor; Thiamphenicol; Porous graphene; $\mathrm{MoS}_{2}$; Molecularly imprinted polymer

\section{$\underline{\text { FULL TEXT }}$}

(C) 2017 The Authors. Published by ESG (www.electrochemsci.org). This article is an open access article distributed under the terms and conditions of the Creative Commons Attribution license (http://creativecommons.org/licenses/by/4.0/). 